\title{
Contrail life cycle and properties from 1 year of MSG/SEVIRI rapid-scan images
}

\author{
M. Vázquez-Navarro ${ }^{1}$, H. Mannstein ${ }^{1, \dagger}$, and S. Kox ${ }^{1, *}$ \\ ${ }^{1}$ Deutsches Zentrum für Luft- und Raumfahrt, Institut für Physik der Atmosphäre, Oberpfaffenhofen, Germany \\ * now at: European Organisation for the Exploitation of Meteorological Satellites (EUMETSAT), Darmstadt, Germany \\ $\dagger$ deceased \\ Correspondence to: M. Vázquez-Navarro (margarita.vazquez@dlr.de)
}

Received: 26 September 2014 - Published in Atmos. Chem. Phys. Discuss.: 10 March 2015

Revised: 18 May 2015 - Accepted: 10 June 2015 - Published: 10 August 2015

\begin{abstract}
The automatic contrail tracking algorithm (ACTA) - developed to automatically follow contrails as they age, drift and spread - enables the study of a large number of contrails and the evolution of contrail properties with time. In this paper we present a year's worth of tracked contrails, from August 2008 to July 2009 in order to derive statistically significant mean values. The tracking is performed using the 5 min rapid-scan mode of the Spinning Enhanced Visible and Infrared Imager (SEVIRI) on board the Meteosat Second Generation (MSG) satellites. The detection is based on the high spatial resolution of the images provided by the Moderate Resolution Imaging Spectroradiometer on board the Terra satellite (Terra/MODIS), where a contrail detection algorithm (CDA) is applied. The results show the satellite-derived average lifetimes of contrails and contrailcirrus along with the probability density function (PDF) of other geometric characteristics such as mean coverage, distribution and width. In combination with specifically developed algorithms (RRUMS; Rapid Retrieval of Upwelling irradiance from MSG/SEVIRI and COCS (Cirrus Optical properties derived from CALIOP and SEVIRI), explained below) it is possible to derive the radiative forcing (RF), energy forcing $(\mathrm{EF})$, optical thickness $(\tau)$ and altitude of the tracked contrails. Mean values here retrieved are duration, $1 \mathrm{~h}$; length, $130 \mathrm{~km}$; width, $8 \mathrm{~km}$; altitude, $11.7 \mathrm{~km}$; optical thickness, 0.34. Radiative forcing and energy forcing are shown for land/water backgrounds in day/night situations.
\end{abstract}

\section{Introduction}

One of the least understood influences that the air traffic has in the atmosphere results from contrail formation. When the conditions suitable for contrail formation occur, contrails form and spread, therefore increasing the cloud cover (Schumann et al., 2012a). In order to better understand the radiative forcing of contrails and aviation-induced cirrus clouds, it is necessary to thoroughly study their onset, development and the evolution of their physical properties. Despite the attention and numerous studies on radiative forcing (RF) and other properties of contrail and contrail cirrus in the past decades (Bakan et al., 1994; Mannstein et al., 1999; Minnis et al., 2004; Palikonda et al., 2005; Atlas et al., 2006; Meyer et al., 2007; Burkhardt and Kaercher, 2011; Iwabuchi et al., 2012; Duda et al., 2013, etc.), the level of scientific understanding of this particular aspect of aviation is still classified as low, and that of induced contrail cirrus as very low (Lee et al. 2009). The current contrail RF estimates are $0.05 \mathrm{~W} \mathrm{~m}^{-2}$ (including contrail cirrus), with large uncertainties (Stocker et al., 2013). Although this global value may seem small, the local effect is larger in regions with high contrail coverage. The difficulty in distinguishing natural cirrus clouds from aviation-induced cirrus clouds is one of the roots of the problem (Mannstein and Schumann, 2005).

In particular, significant uncertainties are found in the retrieval of optical thickness, $\tau$, directly affecting radiative forcing (Meerkoetter et al., 1999; Kärcher and Burkhardt, 2013). Moreover, $\tau$ varies with the age of the contrail. In a case study of 11 contrail outbreaks, Minnis et al. (2013) derived optical thickness of contrails and contrail cirrus, among 


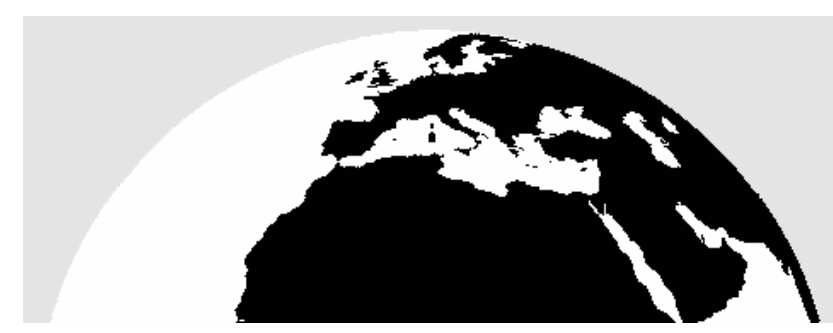

Figure 1. Area covered by the MSG/SEVIRI Rapid Scan Service.

other properties. The mean optical depths of the contrail cirrus under study ranged from 0.32 to 0.43 . They also observed that these values were 2-3 times larger than the corresponding values for the adjacent linear contrails. Not many studies have focused on the observation of contrail-to-contrail-cirrus evolution because, in the absence of a proper tracking technique, the analysis is limited to case studies. Combinations of satellite information and ground-based lidar measurements, such as in the Atlas et al. (2006) case study, show a lifetime of more than $2 \mathrm{~h}$ and a mean optical thickness of 0.35 . Duda et al. (2004) studied the development of contrail clusters over the Great Lakes and derived $\tau$ from 0.1 to 0.6 for contrails that lasted several hours. Graf et al. (2012) studied the cirrus cover cycle and observed timescales between 2.3 to $4.1 \mathrm{~h}$ for contrail cirrus and 1.4 to $2.4 \mathrm{~h}$ for linear contrails.

Satellite imagery provides an excellent tool for observing contrail development. On one hand, polar orbiting satellites have the advantage of a good spatial resolution, which is useful for locating linear contrail structures. On the other hand, geostationary satellites have the capability of observing events that vary in very short timescales. Therefore, a combination of the temporal resolution of geostationary satellites and the spatial resolution of polar orbiting satellites is essential in the study of quick cloud processes. In this paper we have used Terra/MODIS images for the contrail location. It is a polar orbiting instrument with a $1 \times 1 \mathrm{~km}$ nadir resolution. For the tracking and the retrieval of the physical properties we used MSG/SEVIRI (Spinning Enhanced Visible and Infrared Imager (SEVIRI) on board the Meteosat Second Generation (MSG)) (Schmetz et al., 2002), a geostationary instrument with a $3 \mathrm{~km} \times 3 \mathrm{~km}$ nadir resolution. The Rapid Scan Service (RSS) provides MSG/SEVIRI images of the upper third of the MSG disk with a temporal resolution of $5 \mathrm{~min}$; this short time step between two consecutive images makes possible the identification and tracking of single contrail events. The area scanned in the RSS mode is shown in Fig. 1. It covers heavily flown areas such as Europe and part of the North Atlantic Ocean.

In this paper, two main algorithms are used to locate and track the development of contrails: a contrail detection algorithm (CDA) is used for the location (Mannstein et al., 1999) and an automatic contrail tracking algorithm (ACTA) is used for contrail tracking (Vázquez-Navarro et al., 2010). CDA is based on the fact that contrails are ice clouds that have a linear structure when they form. It has already been used to study linear contrail coverage on several regions of the Earth: central Europe (Meyer et al., 2002), North America (Palikonda et al., 2005), eastern North Pacific (Minnis et al., 2005), southern and eastern Asia (Meyer et al., 2007) and the North Atlantic (Graf et al., 2012). A modified version of the algorithm has recently been used by Duda et al. (2013); Bedka et al. (2013) and Spangenberg et al. (2013) to estimate several linear contrail properties in the Northern Hemisphere.

When they are past the linear stage, contrails spread and lose their distinct shape and the CDA can no longer detect them. At first sight, these aged contrails are indistinguishable from natural cirrus clouds, but it is possible to continue tracking them by combining the information on location and displacement when such data are available. The ACTA tracks these linear contrails in a similar way as a human observer does. It considers that contrails in consecutive images retain most of their shape while only changing slightly, and uses this information to identify a given contrail throughout its lifetime. The combined use of CDA on Terra/MODIS and ACTA on MSG/SEVIRI(RSS) provides information on the lifespan of contrails and also on distribution, width and length. The next section describes the exact settings of the CDA used as well as a thorough description of the combination of ACTA and CDA.

Two recently developed algorithms to derive cloud properties are additionally used in this paper to retrieve contrail radiative forcing, energy forcing, optical thickness and cloud top height: RRUMS (Rapid Retrieval of Upwelling irradiance from MSG/SEVIRI, Vázquez-Navarro et al., 2013) and COCS (Cirrus Optical properties derived from CALIOP and SEVIRI, Kox et al., 2014). The RRUMS algorithm measures outgoing top-of-atmosphere (TOA) reflected solar radiation (RSR) and outgoing long-wave radiation (OLR) using SEVIRI channels. The forcing can be derived from this information using a background assumption explained below. The COCS algorithm retrieves optical thickness and top altitude of cirrus clouds through a combination of SEVIRI infrared channels. Both algorithms are described in detail below.

The following sections explain in detail the algorithms used for the production of the data set and the retrieval of the contrail properties. This is followed by an analysis of the obtained results. Note that throughout this paper, the word contrail refers both to linear contrail and contrail cirrus.

\section{Algorithms and data description}

\subsection{CDA and ACTA}

To create the contrail data set, we first applied CDA (Mannstein et al., 1999) to the MODIS data to take advantage of the improved spatial resolution. The CDA was initially developed for use on the Advanced Very High Resolution 
Radiometer carried on NOAA satellites (NOAA/AVHRR). It is based both on the brightness temperature difference, BTD, between the 10.8 and $12 \mu \mathrm{m}$ channels and on the $12 \mu \mathrm{m}$ brightness temperature. Ice crystals present different behaviours in those two wavelengths while other atmospheric and surface properties are similar for both channels (Lee, 1989). Images are processed and normalised, and the resulting scenes are screened for linear contrails using a filter with a kernel size of $19 \times 19$ pixels in several directions to include all possible orientations of the contrails. Finally, the features fulfilling a given set of geometrical and physical thresholds are identified and labelled as linear contrails. The resulting linear contrails will then be used as input for the tracking algorithm.

To create a database with the highest number of automatically tracked contrails and the least possible human intervention, it was necessary to adapt the CDA to produce the lowest false alarm rate possible. This decision has lead inevitably to a lower detection efficiency. The geometrical thresholds used in CDA for this work are a minimum length threshold (47 MODIS pixels), a minimum number of pixels threshold (19 pixels) and an alignment threshold (correlation coefficient $>0.975$ ). Threshold lengths larger than the minimum-number-of-pixels threshold allow the contrail to be a non-connected structure. The physical thresholds are scene-dependent and are related to the sum of the normalised images, the brightness temperature difference and the gradient of the temperature in channel $12 \mu \mathrm{m}$. The output of CDA is a list with the geographical position of $N$ linear contrails.

Having located the $N$ MODIS linear contrails, we mapped them on the SEVIRI grid. A constant height of $10 \mathrm{~km}$ for each contrail was considered for the parallax correction. Then, ACTA (Vázquez-Navarro et al., 2010) was applied to the aforementioned contrails. ACTA is based exclusively on the BTD between SEVIRI infrared channels 10.8 and $12.0 \mu \mathrm{m}$. Based on the position of the starting contrail $C_{i}$ at time $t=t_{0}$, ACTA looks for the same contrail $C_{i}$ in the following SEVIRI image, at time $t+\Delta t: C_{i}(t+\Delta t)$. If found, ACTA uses the information about the new position to continue iterating, now using $t+\Delta t$ as initial time. When the contrail $C_{i}$ cannot be tracked any longer, ACTA returns to $t_{0}$ and repeats the process backwards in time $(t-\Delta t)$. When the backwards tracking is completed, ACTA proceeds to the next contrail on the input list. This procedure allows the determination of the contrail lifetime, $n \Delta t+n^{\prime} \Delta t$, from its first occurrence in SEVIRI at time $t_{0}-n \Delta t$ until it can no longer be discriminated from its surroundings by the satellite at $t_{0}+n^{\prime} \Delta t$, regardless of the MODIS overpass time $t_{0}$ (see schematic representation of ACTA in Fig. 2). Tracking takes place while there is a contrast between contrail and background in the BTD image. A lack of contrast causes the tracking to stop. This could be due to contrails thinning out becoming indistinguishable, evolution of a cluster containing a group of contrails into a widespread homogeneous cirrus cloud, contrails drifting under pre-existing cirrus cloud, etc.

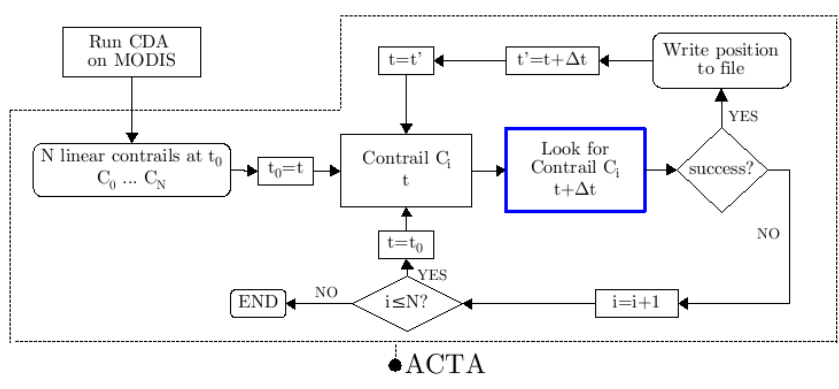

Figure 2. Schematic representation of ACTA. Input: list of linear contrails detected by the CDA on MODIS (Vázquez-Navarro et al., 2010).

Some of the contrails are sufficiently resolved for MODIS (nadir resolution $1 \times 1 \mathrm{~km}$ ) but not enough for SEVIRI (nadir resolution $3 \times 3 \mathrm{~km}$ ). This causes some of the input contrail scenes in SEVIRI to be empty. Further problems such as wrong identification of contrails by the CDA, for instance, coastlines or linear-shaped cloud streaks, were also present. Despite tuning the CDA to reduce the number of false detections, these problems required the intervention of a human observer to eliminate from the starting data set all empty scenes and false detections. The final number of contrails is 2375, which comprises contrails at different development stages. When defining a contrail event as every single contrail occurrence, the data set contains 25179 contrail events. The final number of contrails may appear low given that an entire year is being considered. As stated before, the tuning of CDA to achieve the highest possible accuracy in favour of low human intervention takes an inevitable toll on the detection efficiency. Nevertheless, we consider both values sufficient for a statistical/automatic analysis of contrail evolution and properties. We acknowledge that due to the necessary contrast required for the tracking, the data set may be biased to wider and thicker contrails. Contrails clusters and contrails over non-uniform surface types are underrepresented.

This data set allows us to characterise the contrails according to their width, length, distribution and lifetime. The retrieval of optical thickness, top altitude, radiative forcing and energy forcing is achieved through combination with the additional algorithms already mentioned: COCS and RRUMS.

\subsection{COCS and RRUMS}

The COCS algorithm (Kox et al., 2014) is based on a backpropagation neural network that retrieves ice optical thickness, $\tau$, at $532 \mathrm{~nm}$ and cirrus top altitude using the thermal infrared channels of SEVIRI. The choice of channels enables day- and nighttime retrieval of both properties. The training data set for the neural network uses $\tau$ and cirrus top altitude measurements from CALIOP (Cloud-Aerosol with Orthogonal Polarization) on board the CALIPSO (Cloud-Aerosol Lidar and Infrared Pathfinder Satellite Observations) satel- 

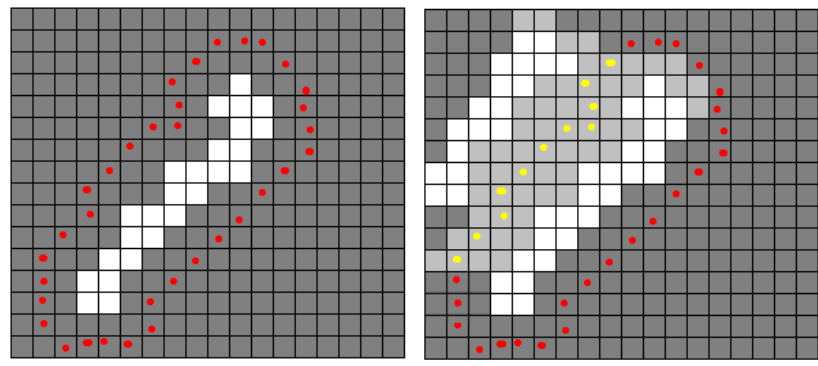

Figure 3. Left: schematic representation of an isolated contrail (white), its background (dark grey) and the pixels considered as the reference state (red). Right: schematic representation of two contrails (white) forming a cluster (light grey). Pixels in the cluster (yellow) must be excluded and only pixels marked in red must be considered as the reference state.

lite coincident with the SEVIRI scans. The validation with an independent data set of coincident CALIOP and COCS measurements showed for $\tau>0.1$ a very low false alarm rate (less than $5 \%$ ) and a very high detection efficiency (larger than $99 \%$ ). This was not the case for lower $\tau$ values. Therefore, the lowest $\tau$ that is here derived from COCS is 0.1 .

RRUMS (Vázquez-Navarro et al., 2013) uses two different methods to retrieve the TOA irradiance for the solar (RSR) and thermal (OLR) parts of the spectrum. Both are based exclusively on combinations of SEVIRI channels. To compute the RSR, a neural network based on the low-resolution solar SEVIRI channels $(600,800 \mathrm{~nm}$ and $1.6 \mu \mathrm{m})$ is used. For the OLR, RRUMS uses a multi-linear fit combining all thermal SEVIRI channels. The algorithm has been successfully validated by comparison with irradiance measurements from Terra/CERES (Clouds and the Earth's Radiant Energy System) (Loeb et al., 2005) and MSG/GERB (Geostationary Earth Radiation Budget) (Harries et al., 2005). In Schumann and Graf (2013) it is shown that regional mean RRUMS OLR agrees with regional mean OLR from ECMWF (European Centre for Medium-Range Weather Forecasts), ERBE (Earth Radiation Budget Experiment) and GERB. The spatial resolution of RRUMS is $3 \times 3 \mathrm{~km}$ at the sub-satellite point, considerably improving that of CERES $(20 \times 20 \mathrm{~km})$ and GERB $(45 \times 45 \mathrm{~km})$. Running this algorithm on our data set allows us to derive radiative forcing and energy forcing as shown below.

The instantaneous radiative forcing (RF) of a contrail is defined as a difference between the TOA outgoing flux caused by the contrail and the outgoing flux in the same exact location in absence of the contrail:

$\mathrm{RF}=F_{\mathrm{bg}}-F_{\mathrm{con}}$,

where $F_{\mathrm{bg}}$ and $F_{\mathrm{con}}$ are the TOA outgoing shortwave or longwave fluxes for the background and the contrail, respectively. The definition requires the knowledge of the background state of the atmosphere had the contrail not been formed. As it is not possible to obtain this information directly from

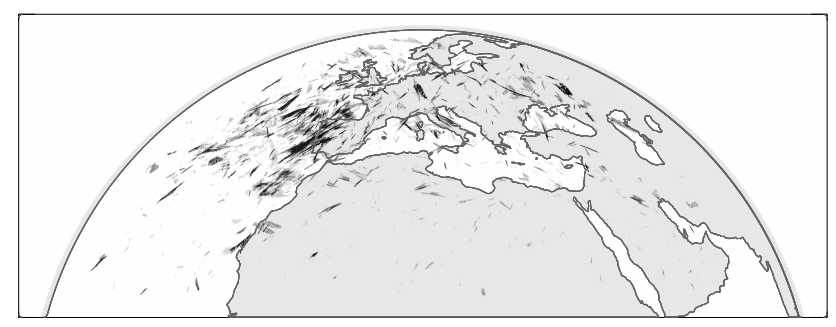

Figure 4. overage of the 2375 tracked contrails. The darker shades of blue indicate a larger number of contrails.

the satellite image, an assumption must be made using a selection of the neighbouring pixels. In the past, similar approaches have been carried out (Palikonda et al., 2005), but must be adapted to the characteristics of our data set. In Palikonda et al. (2005) all pixels surrounding the linear contrail within a one-pixel distance were considered the background. However, in our case, as aged contrail systems or clusters may be involved, their approach would include pixels that are covered by aviation-induced cloudiness, which we must exclude (see Fig. 3). Therefore, the selection of the surrounding pixels is carried out as follows: first, all pixels within a onepixel distance from the contrail are identified and then those that are more representative of the atmospheric background state are selected. The criterion for daytime and nighttime scenes varies. At daytime, the atmosphere background state is given by the average of the $40 \%$ darkest pixels (the pixels reflecting less solar radiation according to RRUMS). If, in this scenario, the contrail appears over a cloud-free area, those pixels will represent the background. If it appears over a partially cloudy area, the $40 \%$ criterion will favour ground pixels over cloudy pixels while also partially accounting for the background cloudiness. This criterion excludes the thin cloud cover that contrail clusters form. Finally, should the contrail form over a thick cloud layer, then selecting $40 \%$ or a different amount of pixels will not make a difference. At nighttime the background is considered to be the average of the $40 \%$ warmest pixels (the pixels emitting more thermal radiation according to RRUMS).

The use of the warm pixel method at daytime would lead to errors. The land background is notably warmer at daytime than at nighttime and the RRUMS method tends to overestimate the SW flux emission of warm bright surfaces. If the method were used, the signal issued by the background would be stronger than it is in reality, leading to stronger contrail forcing. In order to achieve better characterisation of the results, it has therefore been decided to use different criteria for day and night rather than using different criteria for long-wave (LW) and shortwave (SW) forcing depending on the background.

Other background selection criteria have been tested and discarded. Using cirrus masks to discriminate proved not to be sensitive enough. Temperature-based criteria equal for day 

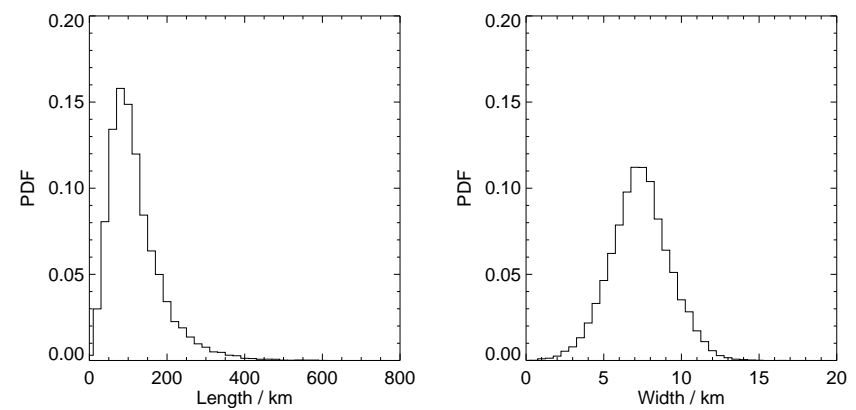

Figure 5. Probability density function of the effective length and width of the contrails studied.

and night lead to stronger SW forcing through the RRUMS warm bright surface flux overestimation. Statistical analysis of the irradiance of the surrounding pixels such as taking the mean irradiance and the values within one standard deviation without any further assumption on the background behaviour also lead to errors. In this case, the contribution of contrail pixels not detected as such by ACTA biased the background forcing calculations. Different distances to the contrail pixels and/or pixel irradiance of previous images were also unsuccessfully considered.

When exclusively using satellite imagery for the assessment of the contrail RF, the impossibility of directly retrieving the background contribution arises. The high variability of scenes - inherent to the problem we are trying to solve does not allow for a simple straightforward solution. We find that our one-pixel approach and background assumption with a daytime and nighttime discrimination proved to be the best choice.

Energy forcing, EF, measures the amount of energy introduced into the Earth-atmosphere system during the lifetime of the contrail that forms along the flight path (Schumann et al., 2011, 2012a). It is an assessment of the climate impact by each contrail-producing flight in terms of the amount of energy per flight distance. EF can be calculated from our data set through Eq. (2), where RF is the radiative forcing, $W$ is the contrail width and the integral runs from the moment of contrail formation (in our case, time of first observation in the satellite image) until dissipation. The EF is computed in units of energy per unit length.

$\mathrm{EF}=\int_{\text {lifetime }} \mathrm{RF}(t, s) \cdot W(t, s) d t$

A typical value for a contrail whose lifetime is $10000 \mathrm{~s}$, has a $1 \mathrm{~km}$ width and produces a net RF of $10 \mathrm{~W} \mathrm{~m}^{-2}$ is $100 \mathrm{GJ} \mathrm{km}^{-1}$ (Schumann et al., 2012a). However, the variability of the EF is very large; it can reach several thousand $\mathrm{GJ} \mathrm{km}^{-1}$ warming or cooling for single route segments because of weather-dependent RF values and because of different contrail lifetimes (Matthes et al., 2012).

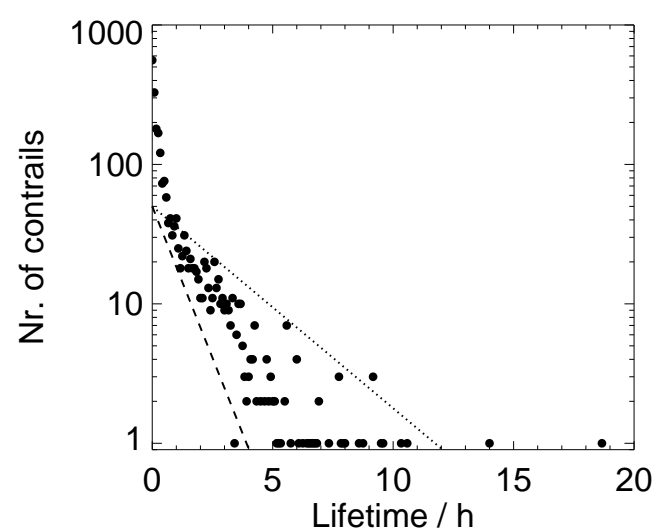

Figure 6. Lifetimes of the contrails studied. Dashed line: $e$-folding time $3 \mathrm{~h}$. Dotted line: $e$-folding time $1 \mathrm{~h}$.

\section{Results}

The data set consists of 25179 contrail events issued from the 2375 contrails detected by the CDA on Terra/MODIS and tracked by ACTA on MSG/SEVIRI (Rapid Scan Service). The following information has been retrieved for each contrail and contrail event: location, length, width, radiative forcing (RF), energy forcing (EF), optical thickness $(\tau)$ and contrail top altitude.

\subsection{Location}

The distribution of the contrails depends solely on the Terra/MODIS overpass time (descending mode: 10:30 local solar time at the Equator, ascending mode: 22:30 local solar time), which is the initial tracking start time. Contrails can remain linear for several hours, so the fact that the overpass occurs only at two specific times of the day provides a collection of contrails formed at different times before the overpass. The data set contains a mixed set of contrails formed at different moments, thanks to the ability of ACTA to track the contrails back and forth in time. Figure 4 shows the location of the tracked contrails. The distribution of the tracked contrails does not directly correspond with the actual air traffic pattern, although some of the expected maxima such as west of the Iberian Peninsula and flights towards to South America are observed. We believe the non-uniformity of the surface over Europe, with its many irregular coastlines, making detection difficult, plays a role in the decreased coverage over central Europe. It must be kept in mind that contrails can only be tracked when originally present in a linear form at the time of the overpass. The observed distribution, however, shows a similarity with the geographical distribution of the ice supersaturated regions shown in Spichtinger et al. (2003). 


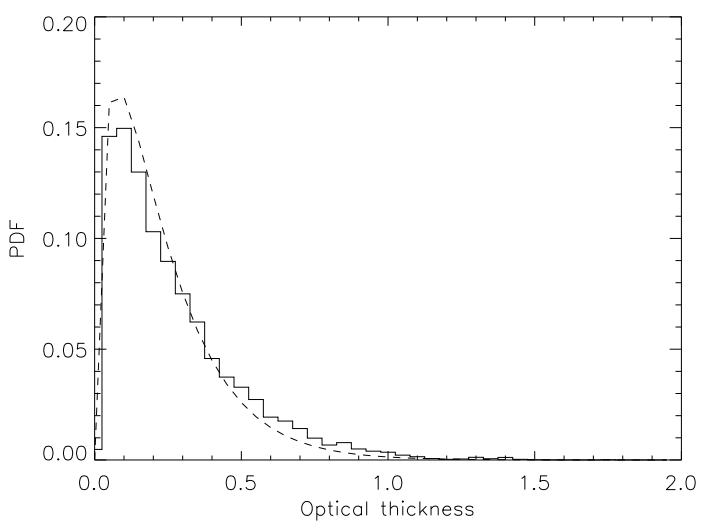

Figure 7. Probability density function of the optical thickness of the tracked contrails. The dashed line represents the probability density function of the gamma distribution (see text).

\subsection{Length and width}

The characteristic length and width of each contrail event is shown in Fig. 5. Contrail length is computed as the distance between the two most distant pixels of the scene. The average length, $130 \mathrm{~km}$ (standard deviation, $72 \mathrm{~km}$ ), is consistent with the mean path length of ice supersaturated regions in the upper troposphere/lower stratosphere (UTLS) region of $150 \mathrm{~km}$ (Gierens and Spichtinger, 2000). Iwabuchi et al. (2012) retrieved a considerably longer average contrail length of $264 \mathrm{~km}$ (standard deviation 294) for contrails over the Northern Hemisphere using MODIS. However, the PDF of their contrails has a mode at $50-100 \mathrm{~km}$, as do the contrails in our data set.

The contrail width is computed as the total contrail area covered by the contrail pixels divided by the length. Hence, in certain cases, this effective width may lead to a value narrower than the pixel width itself. The average width obtained here is $7.8 \mathrm{~km}$ (standard deviation, $2.0 \mathrm{~km}$ ). It is possible to compare our findings with the study by Duda et al. (2013) where three different masks were implemented to examine contrail coverage. The widths they derived ranged from $3.75 \mathrm{~km}$ (most restrictive mask, exclusively linear contrails) to $5.23 \mathrm{~km}$ (some contrail cirrus included). Our result show larger widths not only because the pixel size is larger (SEVIRI vs. MODIS), but also because more contrail cirrus clouds are considered. Assuming an initial width of $60 \mathrm{~m}$ and a spreading rate of $50 \mathrm{~m} \mathrm{~min}^{-1}$, our average width is reached slightly after $2.5 \mathrm{~h}$. The spreading rate observed by Duda et al. (2004) in the case study over the Great Lakes, $2.7 \mathrm{~km} \mathrm{~h}^{-1}$, applied to our case would mean that the $7.8 \mathrm{~km}$ average width is reached after $2.8 \mathrm{~h}$. Please note that the findings described in this paper apply to this subset of contrails.

\subsection{Lifetime}

The most important result that can be obtained with the help of ACTA is the contrail lifetime. Until now, it was possible to characterise linear contrails but little was known about their temporal evolution, with the exception of case studies such as the ones mentioned earlier. Figure 6 shows the distribution of the contrail lifetimes, along with the $e$-folding times corresponding to 1 (dashed) and $3 \mathrm{~h}$ (dotted). The average lifetime of the complete data set is $54.6 \mathrm{~min}$. This value includes the large number of contrails that are not tracked past their initial stages due to the difficult scene characteristics.

Excluding the contrails that, due to scene (or ACTA) limitations, cannot be tracked in more than one scene, the average lifetime is $70.5 \mathrm{~min}$. The $e$-folding times lines show that a typical value for the contrails that can be tracked lies in the $2 \mathrm{~h}$ range.

\subsection{Optical thickness and cloud height}

The combination of ACTA and COCS provides information on the optical thickness, $\tau$, and the altitude of the tracked contrails. Figure 7 shows the PDF of $\tau$ values of the tracked contrails. The mean $\tau$ in our data set is 0.34 with a median value of 0.24 . Although the minimum reliable $\tau$ issued from COCS is $0.1,17 \%$ of all contrail pixels had a COCS $\tau$ below 0.1 . Only $2 \%$ of the pixels have a $\tau>1$. The PDF behaviour is similar to the Iwabuchi et al. (2012) findings, where $\tau$ was retrieved directly from CALIOP data even though they take into account only linear contrails. The average $\tau$ they retrieved is 0.19 . For the sake of comparison with future works, the probability density function of a fitted gamma distribution defined as follows (Eq. 3) is also shown.

$f(\tau)=\frac{\tau^{\gamma-1} e^{-\tau / \mu}}{\mu^{\gamma} \Gamma(\gamma)}$

$\Gamma$ is the gamma function, and the shape, $\gamma$, and scale, $\mu$, parameters in our case are 1.5 and 0.151 , respectively. Bedka et al. (2013), using a modified CDA on Aqua/MODIS, retrieved an average $\tau$ of linear contrails of 0.216 . Minnis et al. (2013) closely analysed 11 contrail outbreaks using Terra and Aqua MODIS data and derived $\tau$ values of contrail cirrus ranging from 0.32 to 0.43 and $\tau$ values of linear contrails between 0.13 and 0.17 . The in situ measurements of $\tau$ taken by Voigt et al. (2011) are also consistent with our findings. Further methods of deriving optical thickness show smaller average values: the model simulations by (Kaercher et al., 2010) yield mean values typically around 0.1 due to the amount of sub-visible contrails considered.

Figure 8 (left) shows the PDF of the optical thickness for three different age categories: younger than $30 \mathrm{~min}$ (solid line, $30 \%$ of the total contrail events in the data set), between 3 and $5 \mathrm{~h}$ (dashed line, $9 \%$ of the total) and older than $8 \mathrm{~h}$ (dotted line, $1.5 \%$ of the total). The distribution of the 

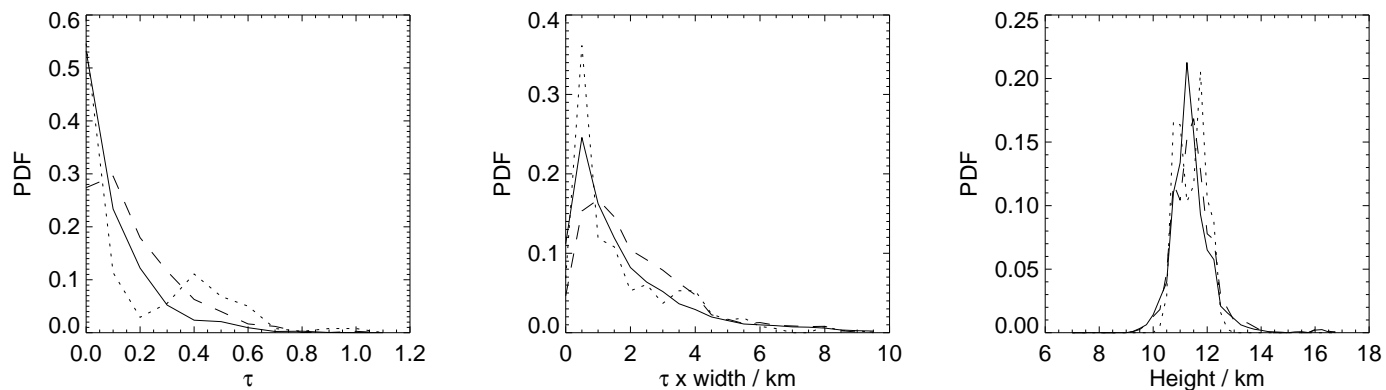

Figure 8. Histograms of the optical depth, $\tau$ (left), the product of $\tau$ and width (centre) and the height above sea level (right) for different contrail ages. Solid line: younger than $30 \mathrm{~min}$; dashed: 3 to $5 \mathrm{~h}$; dotted: longer than $8 \mathrm{~h}$.
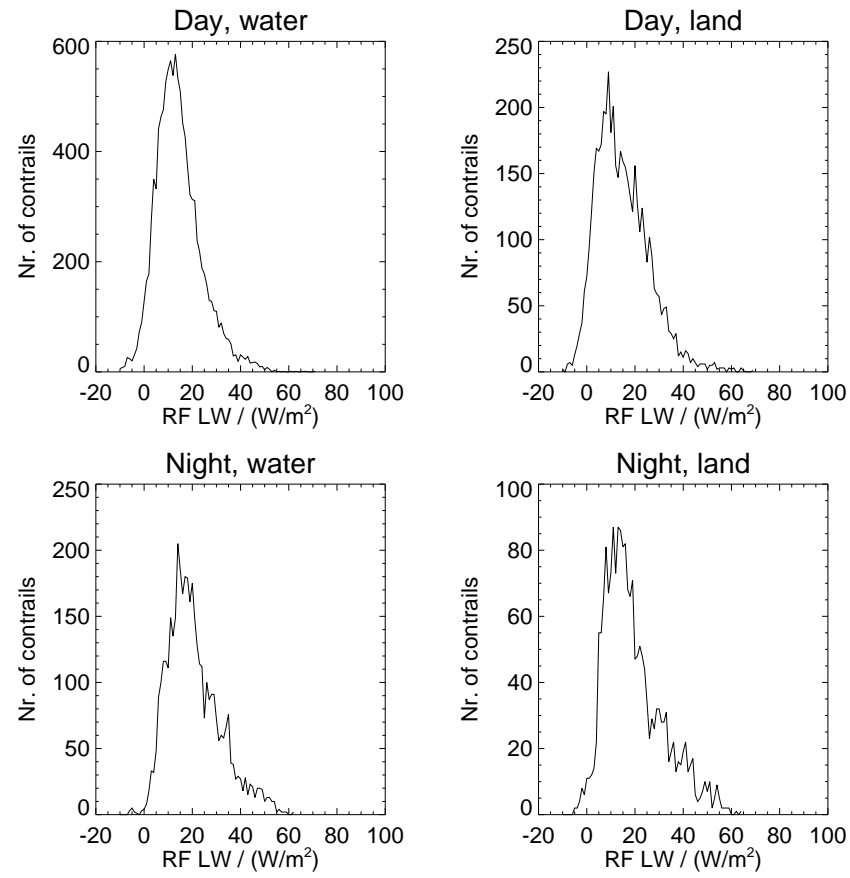

Figure 9. Frequency of occurrence of LW radiative forcing for the tracked contrails.

young (linear) contrails shows the expected behaviour: linear contrails are mainly optically thin. With time (dashed line), contrails allowed to grow under favourable atmospheric conditions adopt a less steep distribution curve. Most of the oldest contrails under study (dotted line) have a very low $\tau$. A secondary maximum in the distribution is caused by contrails within clusters or growing into pre-existing cirrus clouds. In those cases, $\tau$ is strongly influenced by the surroundings and no general conclusions can be drawn. The main observation, the optical thickness decrease with age, is expected and has been shown in numerical simulations such as Unterstrasser and K. Gierens (2010): the longer a contrail lives, the more it is likely to spread, and in the long term it will be optically thinner.
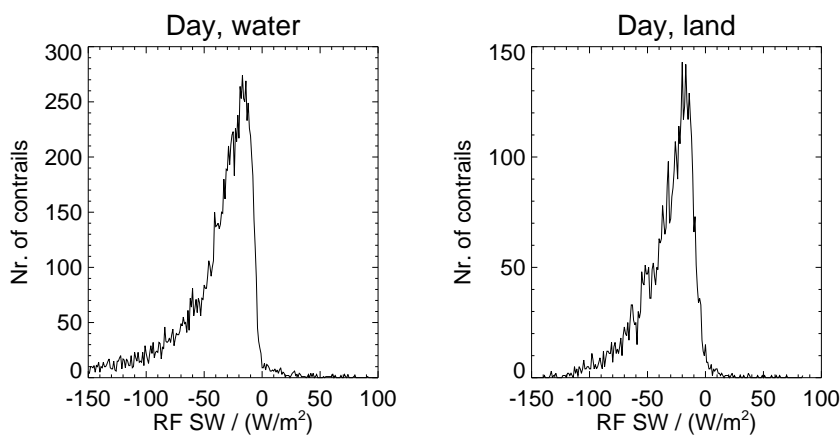

Figure 10. Frequency of occurrence of daytime SW RF for the tracked contrails. Nighttime SW RF (not shown) is 0 .

To stress this result we show the product of optical thickness and width in Fig. 8 (centre) for the same three categories. It can be seen that, on average, the longer a contrail lives, this product becomes lower in spite of the increasing width.

The last graph on the right in Fig. 8 shows the relationship between altitude and contrail age. The altitude is consistent with expected values: mean value $11.7 \mathrm{~km}$, with $0.9 \mathrm{~km}$ standard deviation. Similar values are shown by Iwabuchi et al. (2012): $10.9 \mathrm{~km}$ with a standard deviation of $1 \mathrm{~km}$. The temporal evolution of the altitude does not show any conclusive results on the fall rates. The vertical resolution provided by COCS is insufficient to resolve fall speeds. The top altitude retrieval of the COCS algorithm presents a standard deviation of $750 \mathrm{~m}$ whereas the observations of contrail fall rates lie in the $0.045 \mathrm{~m} \mathrm{~s}^{-1}$ range (Duda et al., 2004).

\subsection{Radiative forcing and energy forcing}

The radiative forcing is shown in Table 1. The units are Watt per square metre of contrail area, i.e. the values correspond to a sky that is $100 \%$ covered by contrails. A combined net radiative forcing value is not shown because the actual contrail coverage does not correspond with the spatial distribution of our tracked contrails. As it has been pointed out before, the location of the contrails depends on the MODIS over- 


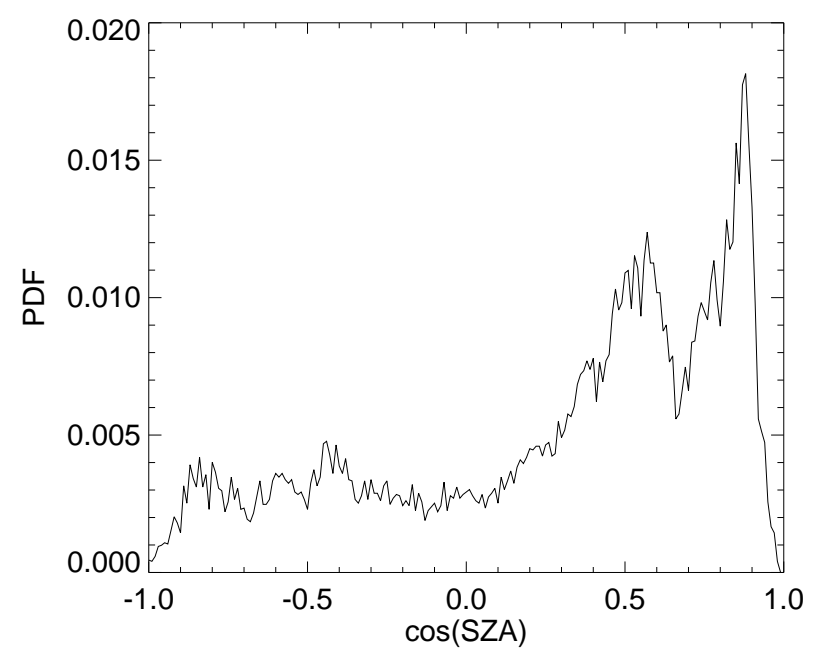

Figure 11. Probability density function of the cosine of solar zenith angle corresponding to the contrails in the data set.

pass time and does not reproduce the actual traffic pattern. Moreover, the criterion for background assessment at daytime is different than the nighttime criterion, so showing a mean value from the data set would be misleading. Instead, the analysis focuses on two different backgrounds (land/sea) under two different conditions (day/night). The median value is chosen instead of the mean in order to use a parameter that is more representative of the distribution and less sensitive to outliers. It can be seen that the net daytime forcing is the balance between two large quantities of different signs where the SW contribution outweighs the LW leading to a net radiative cooling. At nighttime there is no reflected solar radiation, which causes contrails to have a net radiative warming effect. Please note that following contrails have been excluded from the results: those extending over both land and water backgrounds and those under extreme solar zenith angles (dusk/dawn).

The variability of the LW forcing is large, as seen on the frequency distribution plots in Fig. 9. The median value here derived for the LW RF ranges between 13 and $19 \mathrm{~W} \mathrm{~m}^{-2}$ depending on the time of the day and the background. Previous works show similar forcings, such as in Palikonda et al. (2005) (12 to $27 \mathrm{~W} \mathrm{~m}^{-2}$, from MODIS/AVHRR data). However, direct comparison with previous works must be carried out carefully because RF varies greatly depending on the surroundings and on the time of the day. Model-based studies on the LW such as Meerkoetter et al. (1999) and Stuber and Forster (2007) consider that the mean LW forcing easily reaches 40 or $50 \mathrm{~W} \mathrm{~m}^{-2}$ over a cloud-free continental midlatitude summer atmosphere. More recent studies involving contrails detected by the MODIS instrument and modelled backgrounds range between 11 and $18 \mathrm{~W} \mathrm{~m}^{-2}$ (Spangenberg et al., 2013).

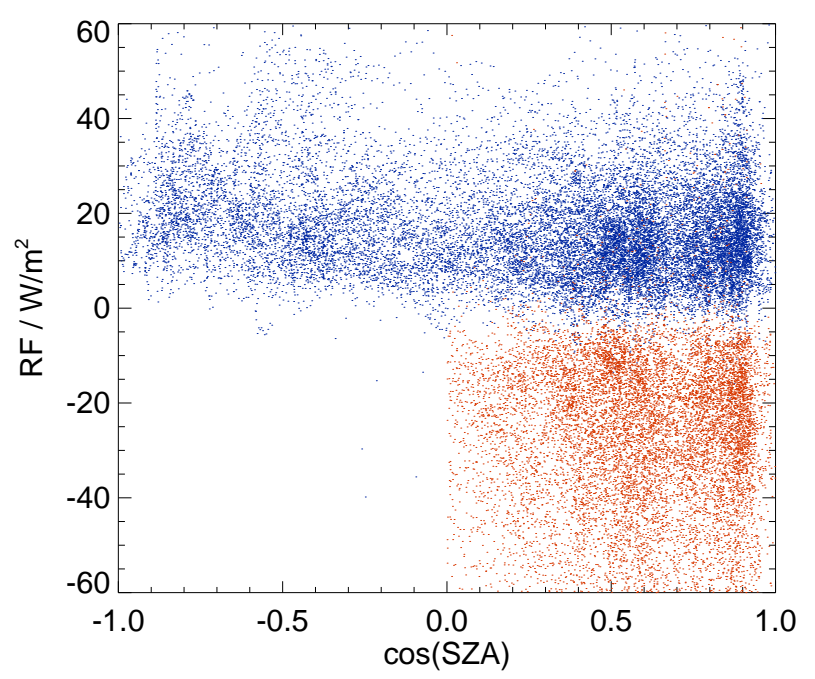

Figure 12. Radiative forcing (blue: LW, red: SW) vs. cosine of the solar zenith angle (SZA) corresponding to the contrails in the data set.

The distribution of the SW RF also presents large variability (see Fig. 10). The median SW RF forcing between -26 and $-28 \mathrm{~W} \mathrm{~m}^{-2}$ found here is slightly stronger than expected. The reasons are twofold: overestimations by the RRUMS RSR algorithm over warm bright surfaces (Vázquez-Navarro et al., 2013) and the nature of our input data set. Shortwave RF depends on the solar zenith angle. Our contrails are found shortly before noon, which leads to higher SW RF values (see Figs. 11 and 12). The RF distribution peaks around $-20 \mathrm{~W} \mathrm{~m}^{-2}$ and quickly decreases.

The low fraction of negative RF LW values $(2.6 \%)$ and positive RF SW values ( $2 \%$ ) present in the RF distribution plots evidences the difficulty of choosing the right background pixels.

The behaviour of the RF with respect to the optical thickness is shown in Fig. 13 for both the LW (blue) and the SW (red) ranges. The darker colours indicate a higher number of occurrences. Despite the great variability of the data set, it can be clearly seen that for higher $\tau$ values both forcings increase. When $\tau$ approaches 0 , the forcings tend to zero. This is also shown by the results of a parameterised analytical model described in Schumann et al. (2012b).

The energy forcing is shown in Table 2. The large amount of energy inserted in (or removed from) the atmosphere through the presence of a contrail until it dissipates can be observed. The observed energy forcing exceeding $500 \mathrm{GJ} \mathrm{km}^{-1}$ shows that a few big contrails contribute considerably to the overall climate impact of contrails. The percentage of contrails over land/water at day/nighttime is slightly different than in the RF case because the EF takes into account the effect of the contrail during its entire lifetime; contrails that drift from land to water (or vice versa) during their evolution have been removed from the analysis. 
Table 1. Radiative day- and nighttime forcing of the tracked contrails (median values). In percent, the fraction of contrails in each case.

\begin{tabular}{lrrrr|rrrr}
\hline & \multicolumn{4}{c|}{ Daytime RF $\left(\mathrm{W} \mathrm{m}^{-2}\right)$} & \multicolumn{4}{|c}{ Nighttime $\mathrm{RF}\left(\mathrm{W} \mathrm{m}^{-2}\right)$} \\
\hline & $\mathrm{LW}$ & $\mathrm{SW}$ & Net & Frac. & LW & SW & Net & Frac. \\
Land & 13.75 & -26.91 & -13.16 & $19.0 \%$ & 16.89 & 0 & 16.89 & $7.8 \%$ \\
Water & 13.53 & -28.68 & -15.15 & $45.0 \%$ & 19.12 & 0 & 19.12 & $16.3 \%$ \\
\hline
\end{tabular}

Table 2. Day- and nighttime energy forcing. In percent, the fraction of contrails in each case.

\begin{tabular}{lrrrr|rrrr}
\hline \multicolumn{4}{c|}{ Daytime EF $\left(\mathrm{GJ} \mathrm{km}^{-1}\right)$} & \multicolumn{4}{c}{ Nighttime EF $\left(\mathrm{GJ} \mathrm{km}^{-1}\right)$} \\
\hline & LW & SW & Net & Frac. & LW & SW & Net & Frac. \\
Land & 267.87 & -610.02 & -342.15 & $18.7 \%$ & 269.83 & 0 & 269.83 & $11.3 \%$ \\
Water & 290.30 & -875.23 & -584.93 & $48.6 \%$ & 403.04 & 0 & 403.04 & $21.3 \%$ \\
\hline
\end{tabular}
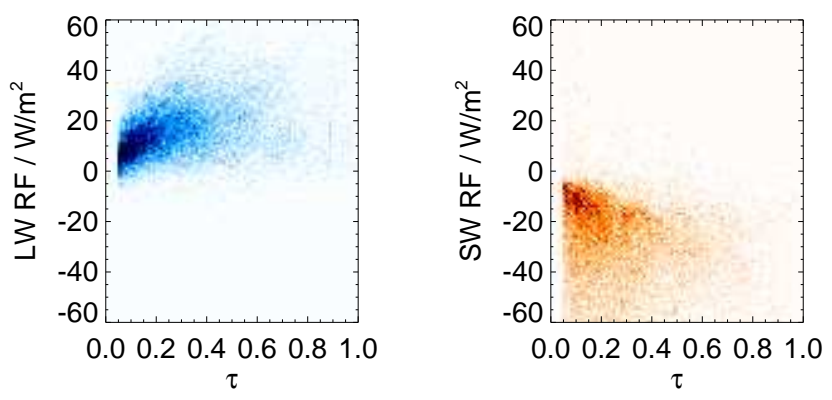

Figure 13. Radiative Forcing vs. $\tau$. Red: SW; blue: LW

\section{Summary and Conclusions}

We have been able to track in time successfully and for the first time over 2300 contrails corresponding to over 25000 events. This has been done combining the CDA detection (Mannstein et al., 1999) and the ACTA tracking (VázquezNavarro et al., 2010) algorithms. The obtained data set comprises short- and long-lived contrails in linear and non-linear stages, resembling nature. The lack of similarity with the air traffic pattern is mainly due to two reasons: the fact that the tracked contrails only issue from Terra/MODIS overpasses and the known limitations in the detection efficiency of CDA. There is known bias towards wider and thicker contrails. Contrail clusters are present in the data set, but may be underrepresented.

Nevertheless, the data set constitutes a representative selection of contrails under different formation conditions and with different properties from satellite images and - thanks to the automatic tracking - the selection includes for the first time clouds that would otherwise be considered natural. Some of the tracked contrails have properties differing from those reported for linear contrails in the past, in particular we found many optically thick and geometrically wide contrails. This stresses the importance of considering both linear con- trails and contrail cirrus together when studying the radiative impact of air-traffic-induced cloudiness.

Several contrail properties have been derived, either directly by using ACTA (width, length, lifetime) or by combining it with other algorithms such as COCS (optical thickness and contrail top altitude) or RRUMS (radiative forcing and energy forcing). The combination with further algorithms to retrieve ice water content or particle size could provide valuable information on the contrail aging process. Information on the contrail temperature is also necessary for further studies.

The findings constitute a valuable data set in which several physical properties of (satellite observed) contrails during their lifetime are analysed. An average contrail/contrail cirrus in the data set has an effective width of $8 \mathrm{~km}$ and a length of $130 \mathrm{~km}$. This length is compatible with the extension of the ice supersaturated layers (Gierens and Spichtinger, 2000). The top altitude lies in the expected range: $11.7 \mathrm{~km}$. The mean $\tau$ is 0.34 .

Comparing with the recent study from Iwabuchi et al. (2012), it can be seen that our data set is formed by shorter contrails $(130 \mathrm{~km}$ vs. $260 \mathrm{~km})$ that are optically thicker $(0.34$ vs. 0.19). The main difference between both data sets is the type of contrail under study and the areas under consideration. Our optical thickness retrieval has a lower boundary of 0.1 , and in their data set $34 \%$ of contrails have $\tau$ below 0.1 . The recent analysis of Bedka et al. (2013) gave a $\tau$ value of 0.2 , with $21 \%$ below 0.1 . The study of contrail outbreaks by Minnis et al. (2013) show optical thicknesses for contrail cirrus ranging from 0.32 to 0.43 , consistent with our findings.

The average contrail lifetime derived (less than $1 \mathrm{~h}$ ) includes contrails that are identified in the SEVIRI grid but cannot be tracked due to difficult scene characteristics or limitations of the ACTA. When not taking those into account, the average lifetime of a contrail is $70 \mathrm{~min}$. This study refers to contrails in SEVIRI satellite images. We are aware that a part of the development of the contrail cannot be observed from this satellite platform due to a low optical thickness (or con- 
trast with the background) and to a sub-pixel width. Several case studies for instruments with a spatial resolution similar to SEVIRI (for example Duda et al., 2004, using GOES imagery) have pointed out that this missing time is close to $1 \mathrm{~h}$. This extra hour is consistent with the fact that the average lifetime of the tracked contrails is around $1 \mathrm{~h}$ (plus the additional initial period not visible from the satellite platform) and the average width is reached after around $2.5 \mathrm{~h}$. Our findings are also in agreement with Graf et al. (2012), who observed maximum cirrus contrail cover over the North Atlantic between 2.1 and $4.1 \mathrm{~h}$ after passage of air traffic.

The radiative forcing derived is in agreement with previous works. In order to compute the contrail radiative forcing, different assumptions on the shortwave and long-wave outgoing flux density have been tested and discussed. As a consequence, no net value is shown but contrails have been classified in four categories combining day/night conditions and land/ocean backgrounds. A similar classification of the optical thickness and height presents similar values in all four categories and is therefore not shown. RF LW median values for the different situations range from 13 to $19 \mathrm{~W} \mathrm{~m}^{-2}$ and RF SW is around $-27 \mathrm{~W} \mathrm{~m}^{-2}$. There are differences between day- and nighttime and also between land and water backgrounds. All RF distributions show a main peak and a long tail. This stresses their large variability of nature and the need to carefully consider the correct contrail-free state of the atmosphere. An additional analysis of the relationship between the forcing and $\tau$ shows, as expected, that the RF is low when the optical thickness approaches 0 but gains importance with increasing $\tau$. A better characterisation of the distribution of the RF values is crucial to model approaches. Due to the nature of the analysis carried out, it is not possible to derive a representative estimate for the net RF value. The different criteria for day- and nighttime background pixel selection prevent from a direct RF SW + RF LW comparison.

Unlike the energy forcing that directly gives information about the average effect of contrails in the atmosphere throughout their lifetime, the radiative forcing is not related to the lifetime of contrails. However, estimates of the global contrail radiative forcing are linked to the contrail coverage, which is inherently related to contrail lifetime. Tracking methods such as ACTA, be they on their own or in combination with other algorithms, provide very valuable information about not only contrail physical properties but also their evolution. The results can help reduce the large uncertainties still existing on the effect of aviation-induced cloudiness in climate.

Acknowledgements. This work contributes to the DLR project WeCARE. The authors would like to thank Ulrich Schumann, Kaspar Graf and Luca Bugliaro for their comments and remarks. We thank Bernhard Mayer for his assistance with libRadtran for RRUMS. This paper is dedicated to the memory of our colleague and mentor Hermann Mannstein.
The article processing charges for this open-access publication were covered by a Research Centre of the Helmholtz Association.

Edited by: S. Buehler

\section{References}

Atlas, D., Wang, Z., and Duda, D. P.: Contrails to cirrus: morphology, microphysics, and radiative properties, J. Appl. Meteorol., 45, 5-19, 2006.

Bakan, S., Betancor, M., Gayler, V., and Grassl, H.: Contrail frequency over Europe from NOAA-satellite images, Ann. Geophys., 12, 962-968, 1994, http://www.ann-geophys.net/12/962/1994/.

Bedka, S. T., Minnis, P., Duda, D. P., Chee, T. L., and Palikonda, R.: Properties of linear contrails in the Northern Hemisphere derived from 2006 Aqua MODIS observations, Geophys. Res. Lett., 40, 772-777, doi:10.1029/2012GL054363, 2013.

Burkhardt, U. and Kaercher, B.: Global radiative forcing from contrail cirrus, Nature Climate Change, 1, 54-58, doi:10.1038/nclimate1068, 2011.

Duda, D. P., Minnis, P., Nguyen, L., and Palikonda, R.: A case study of the development of contrail clusters over the Great Lakes, J. Atmos. Sci., 61, 1132-1146, 2004.

Duda, D. P., Minnis, P., Khlopenkov, K., Chee, T. L., and Boeke, R.: Estimation of 2006 Northern Hemisphere contrail coverage using MODIS data, Geophys. Res. Lett., 40, 612-617, doi:10.1002/grl.50097, 2013.

Gierens, K. and Spichtinger, P.: On the size distribution of icesupersaturated regions in the upper troposphere and lowermost stratosphere, in: Ann. Geophys., 18, 499-504, Springer, 2000.

Graf, K., Schumann, U., Mannstein, H., and Mayer, B.: Aviation induced diurnal North Atlantic cirrus cover cycle, Geophys. Res. Lett., 39, L16804, doi:10.1029/2012GL052590, 2012.

Harries, J. E., Russell, J. E., Hanafin, J. A., Brindley, H., Futyan, J., Rufus, J., Kellock, S., Matthews, G., Wrigley, R., Last, A., Mueller, J., Mossavati, R., Ashmall, J., Sawyer, E., Parker, D., Caldwell, M., Allan, P. M., Smith, A., Bates, M. J., Coan, B., Stewart, B. C., Lepine, D. R., Cornwall, L. A., Corney, D. R., Ricketts, M. J., Drummond, D., Smart, D., Cutler, R., Dewitte, S., Clerbaux, N., Gonzalez, L., Ipe, A., Bertrand, C., Joukoff, A., Crommelynck, D., Nelms, N., Llewellyn-Johnes, D. T., Butcher, G., Smith, G. L., Szewczyk, Z. P., Mlynczak, P. E., Slingo, A., Allan, R. P., and Ringer., M. A.: The Geostationary Earth Radiation Budget Project, B. Am. Meteorol. Soc., 86, 945-960, 2005.

Iwabuchi, H., Yang, P., Liou, K. N., and Minnis, P.: Physical and optical properties of persistent contrails: Climatology and interpretation, J. Geophys. Res., 117, D06215, doi:10.1029/2011JD017020, 2012.

Kaercher, B., Burkhardt, U., Ponater, M., and Fromming, C.: Importance of representing optical depth variability for estimates of global line-shaped contrail radiative forcing, P. Natl. Acad. Sci. USA, 107, 19181-19184, 2010.

Kärcher, B. and Burkhardt, U.: Effects of optical depth variability on contrail radiative forcing, Q. J. R. Meteorol. Soc., 139, 16581664, 2013. 
Kox, S., Bugliaro, L., and Ostler, A.: Retrieval of cirrus cloud optical thickness and top altitude from geostationary remote sensing, Atmos. Meas. Tech., 7, 3233-3246, doi:10.5194/amt-7-32332014, 2014

Lee, D. S., Fahey, D. W., Forster, P. M., Newton, P. J., Wit, R. C. N., Lim, L. L., Owen, B., and Sausen, R.: Aviation and global climate change in the 21st century, Atmos. Environ., 43, 3520 3537, doi:10.1016/j.atmosenv.2009.04.024, 2009.

Lee, T. F.: Jet contrail identification using the AVHRR infrared split window, J. Appl. Meteorol., 28, 993-995, 1989.

Loeb, N. G., Kato, S., Loukachine, K., and Manalo-Smith, N.: Angular Distribution Models for Top-Of-Atmosphere radiative flux estimation from the Clouds and the Earth's Radiant Energy System Instrument on the Terra satellite. Part I: Methodology, J. Atmos. Ocean. Tech., 22, 338-351, 2005.

Mannstein, H. and Schumann, U.: Aircraft induced contrail cirrus over Europe, Meteorol. Z., 14, 549-554, doi:10.1127/09412948/2005/0058, 2005.

Mannstein, H., Meyer, R., and Wendling, P.: Operational Detection of Contrails from NOAA-AVHRR-Data, Int. J. Remote Sens., 20, 1641-1660, 1999.

Matthes, S., Schumann, U., Grewe, V., Frömming, C., Dahlmann, K., Koch, A., and Mannstein, H.: Climate optimized air transport, in: Atmospheric Physics, 727-746, Springer, 2012.

Meerkoetter, R., Schumann, U., Doelling, D. R., Minnis, P., Najakima, T., and Tsushima, Y.: Radiative forcing by contrails, Ann. Geophys., 17, 1080-1094, 1999, http://www.ann-geophys.net/17/1080/1999/.

Meyer, R., Mannstein, H., Meerkoetter, R., Schumann, U., and Wendling, P.: Regional radiative forcing by line-shaped contrails derived from satellite data, J. Geophys. Res., 107, D10, doi:10.1029/2001JD00426, 2002.

Meyer, R., Buell, R., Leiter, C., Mannstein, H., Marquart, S., Oki, T., and Wendling, P.: Contrail observations over Southern and Eastern Asia in NOAA/AVHRR data and comparisons to contrail simulations in a GCM, Int. J. Remote Sens., 28, 2049-2069, 2007.

Minnis, P., Ayers, J. K., Palikonda, R., and Phan, D.: Contrails, Cirrus Trends, and Climate, J. Climate, 17, 1671-1685, 2004

Minnis, P., Palikonda, R., Walter, B. J., Ayers, J. K., and Mannstein, H.: Contrail properties over the eastern North Pacific from AVHRR data, Meteor. Z., 14, 515-523, 2005.

Minnis, P., Bedka, S. T., Duda, D. P., Bedka, K. M., Chee, T., Ayers, J. K., Palikonda, R., Spangenberg, D. A., Khlopenkov, K. V., and Boeke, R.: Linear contrail and contrail cirrus properties determined from satellite data, Geophys. Res. Lett., 40, 3220-3226, 2013.

Palikonda, R., Minnis, P., Duda, D. P., and Mannstein, H.: Contrail coverage derived from 2001 AVHRR data over the continental United States of America and surrounding areas, Meteor. Z., 14, 515-523, 2005.
Schmetz, J., Pili, P., Tjemkes, S., Just, D., Kermann, J., Rota, S., and Ratierk, A.: An introduction to Meteosat Second Generation (MSG), B. Am. Meteorol. Soc., 83, 977-992, 2002.

Schumann, U. and Graf, K.: Aviation-induced cirrus and radiation changes at diurnal timescales, J. Geophys. Res., 118, 2404-2421, 2013.

Schumann, U., Graf, K., and Mannstein, H.: Potential to reduce the climate impact of aviation by flight level changes, in: 3rd AIAA Atmospheric and Space Environments Conference, AIAA paper 2011-3376, doi:10.2514/6.2011-3376, 2011.

Schumann, U., Graf, K., Mannstein, H., and Mayer, B.: Contrails: Visible aviation induced climate impact, in: Atmospheric Physics, 239-257, Springer, 2012a.

Schumann, U., Mayer, B., Graf, K., and Mannstein, H.: A parametric radiative forcing model for contrail cirrus, J. Appl. Meteor., 51, 1391-1406, 2012b.

Spangenberg, D. A., Minnis, P., Bedka, S. T., Palikonda, R., Duda, D. P., and Rose, F. G.: Contrail radiative forcing over the Northern Hemisphere from 2006 Aqua MODIS data, J. Geophys. Res., 40, 595-600, doi:10.1002/grl.50168, 2013.

Spichtinger, P., Gierens, K., and Read, W.: The global distribution of ice-supersaturated regions as seen by the Microwave Limb Sounder, Q. J. R. Meteoroloc. Soc., 129, 3391-3410, 2003.

Stocker, T. F., Qin, D., Plattner, G.-K., Tignor, M., Allen, S. K., Boschung, J., Nauels, A., Xia, Y., Bex, V., and Midgley, P. M.: Climate change 2013: The physical science basis, Intergovernmental Panel on Climate Change, Working Group I Contribution to the IPCC Fifth Assessment Report (AR5)(Cambridge Univ Press, New York), 2013.

Stuber, N. and Forster, P.: The impact of diurnal variations of air traffic on contrail radiative forcing, Atmos. Chem. Phys., 7, 3153-3162, doi:10.5194/acp-7-3153-2007, 2007.

Unterstrasser, S. and Gierens, K.: Numerical simulations of contrail-to-cirrus transition - Part 1: An extensive parametric study, Atmos. Chem. Phys., 10, 2017-2036, doi:10.5194/acp-102017-2010, 2010.

Vázquez-Navarro, M., Mannstein, H., and Mayer, B.: An automatic contrail tracking algorithm, Atmos. Meas. Tech., 3, 1089-1101, doi:10.5194/amt-3-1089-2010, 2010.

Vázquez-Navarro, M., Mayer, B., and Mannstein, H.: A fast method for the retrieval of integrated longwave and shortwave top-of-atmosphere upwelling irradiances from MSG/SEVIRI (RRUMS), Atmos. Meas. Tech., 6, 2627-2640, doi:10.5194/amt6-2627-2013, 2013

Voigt, C., Schumann, U., Jessberger, P., Jurkat, T., Petzold, A., Gayet, J.-F., Krämer, M., Thornberry, T., and Fahey, D.: Extinction and optical depth of contrails, Geophys. Res. Lett., 38, L11806, doi:10.1029/2011GL047189, 2011. 